\title{
Android Solicitation Hinge Automated Wheel Chair for Physically Crippled Persons
}

\author{
J. Boopala', S. Biruntha', S. Senthil Prasath ${ }^{2}$ and K. Senathipathi' \\ ${ }^{1}$ AP/CSE, Sri Krishna College of Engineering and Technology, Coimbatore - 641008, Tamil Nadu, India; \\ boopalacse@gmail.com, banupriya12317@gmail.com, senathipathik@skcet.ac.in \\ 2Pricol Ltd, Coimbatore - 641018, Tamil Nadu, India; ssprasath.india@gmail.com
}

\begin{abstract}
Objectives: The primary purpose of this endeavor is to construct a mechanized chair that helps the physically halting people. These days numerous wheelchairs area unit open with numerous running developments, however the price is high and it's not a lot of prosperous. Methods/Statistical Analysis: Scientists and socialist worked very hard to help the elders and disabled persons to adopt the methods that can help and interact with the society and smooth their mobility during day to day activities that are dependent on others or using the traditional ways like wheelchair. The most part assembling this framework is to conquer some inconvenience of existing structure where the chair is controlled with the assistance of humanoid adaptable application. Findings: The reason for choosing the android stage is that these days android cell phones are usually utilized. From this framework the client needs to initially get associated with the wheelchair with the assistance of use. This framework formed with PIC microcontroller, Bluetooth module and residential robotization framework which enable the client to interface with the chair at totally different components of the management (Left, Right, Forward, Backward and Stop). Substitute parts those are needed within the system Bluetooth module, 12V DC motors, Battery. Application/Improvements: Furthermore, in this Home computerization framework is included request to help the impaired individual on wheelchair to conquer a few conditions so as to turn on and off the fan and light without the outside help of other individual.
\end{abstract}

Keywords: Android, Bluetooth, Automated Wheelchair, Home Automation System, PIC Microcontroller

\section{Introduction}

\subsection{Framework of the Project}

The 2011 enrollment reportable augmentation in country's game plenty by $22.4 \%$ some place within the scope of 2001 and 2011. In 2001 check of hindered was 2.19 large integer in 2001,which to 2.68 large integer in 2011 of that 2.41 large integer square measure of us and 2.01 large integer square measure females. Most of the obstructed square measures those with physical incapacity, representing $20.3 \%$ for all out disabled people. The number of inhabitants in incapacity is expanding because of different reasons as street mishaps, premises fall, suicide endeavors, youth polio assault, catastrophic events, for example, seismic tremors, avalanches, surge and so forth. There ought to be a few methods for machine that could give this populace to move beginning with one place then onto successive with no different individual facilitate. It will give in a constrained situation for example inside the house or outside condition.

\subsection{Brace to the Debilitated People}

In our nation, we have gigantic population where the number of handicapped people needs a help particularly that is given by chair to the debilitated people. The run of the mill pushing chair is that the unrefined one within which the client needs to push the seat with the hands

${ }^{*}$ Author for correspondence 
or else some individual will move the wheelchair. It gives a worry to the client when going for a long separation. So with the assistance of android and human knowledge mechanized wheelchair was advanced. A mechanized wheelchair depends on some information interfacing machine which gives contribution to the engine. The engine forms the information gave from the portable application and makes the relating move (regarding development- push Ahead, Backward, Left and Right).

\section{Literature Survey}

In the present situation numerous tasks are created identified with wheelchair. A portion of the current frameworks depend on the info given by joystick, eye-ball developments, signal based, voice-acknowledgment based, tilt based applications made by hand and cerebrum controlled wheelchairs for example through the nerve flag are delivered ${ }^{1-3}$.

In joystick based mostly chair individual with completely different inadequacies might imagine that it's troublesome to maneuver joystick because it needs broad proportion of intensity what is more it should impact the latency of the chair which can be dangerous. Within the eye-ball developments controlled chair and head or neck developments controlled chair, consumer has confined sight because the movement of the eye-ball or head or neck. For this circumstance, client has unnatural sight because the development of the eye-ball or head or neck is taken as a commitment by system which will offer wrong yield for that case $e^{4-7}$.

Voice controlled framework can give incorrect reaction in uproarious condition and it can

end up troublesome for the shopper to maneuver beginning with one then onto consecutive place. In measuring device- primarily based controlled system, the tilting heading of the mobile ought to be exact to get precise outcome. Besides it will be mind boggling for individuals with inabilities in wrist developments and example acknowledgment based framework will require preparing of the client just as the framework. The preparation of the framework will change for various clients ${ }^{8-10}$.

Likewise in brain signal controlled framework gains and changes over the cerebrum flag to provide guidance signals. This signs are produced because of electrical movement that is invigorated by mind yet brain signal can't be depended on catch the precise flag. What's more, that makes ailment to head through cerebral pain and furthermore it gets the opportunity of making harm to our mind $\stackrel{2-3}{\text {. }}$.

\section{Proposed System}

In our enterprise, the enhancements of the chair area unit controlled with the assistance of an android application.

The projected structure i.e., Figure 1 uses contact screen primarily based android versatile to manage the chair. The humanoid adaptable is expounded with PIC microcontroller fitted within chair through Bluetooth module. They gave application gives basic UI to the client for choice of heading and the developments of wheelchair.

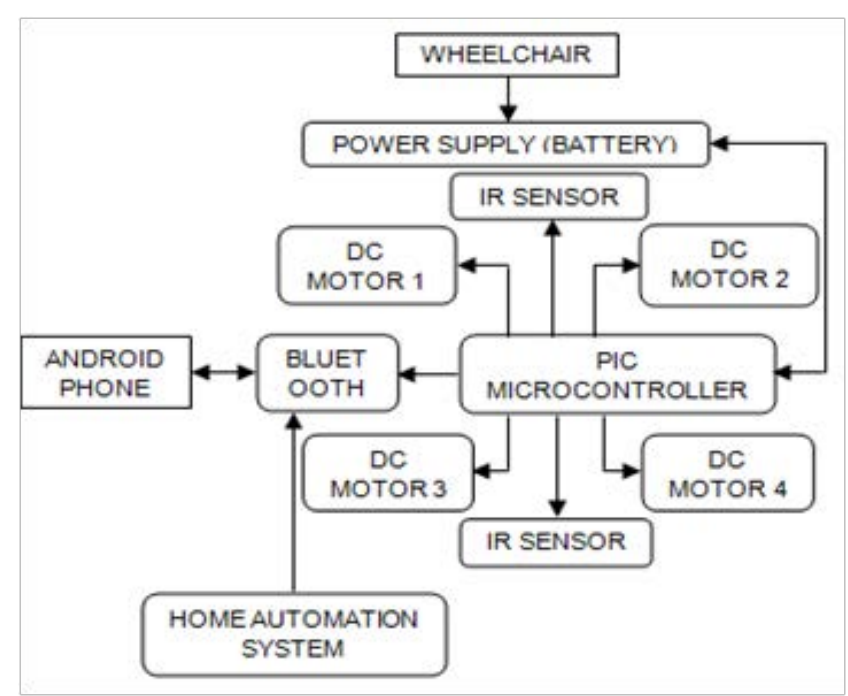

Figure 1. Data flow diagram.

In view of chosen input, the relating signal is shipped through Bluetooth module to the microcontroller that accepts activities as a kind of yield. Within the event that the consumer chooses the forward course, than the entire four engines area unit created to maneuver a similar way and with a similar speed. Also, for the switch for example reverse way is finished. On the off chance that the client needs to move in the Left or Right heading than extremity of all the four engines are turned around correspondingly.

\section{Implementation}

\subsection{Software and Hardware Requirements}

\subsubsection{Hardware Requirement}

- PIC Microcontroller

- HC 05 Bluetooth Module

- IR Sensors 
- Home Automation Kit

- 12V Battery

- 4 DC Motors

- Chair and 4 Wheels

- Android Phone

\subsubsection{Software Requirement}

- Android Studio

- Android Programming

- MPLAPX

\subsection{Implementation Details}

The model of the trip has been created wherever the i.e., Figure 2 at a lower place depicts the proportionate. The i.e., Figure 1 appeared underneath will appear the application which has been developed to ensure the connectivity with android phone and the prototype that has been developed.

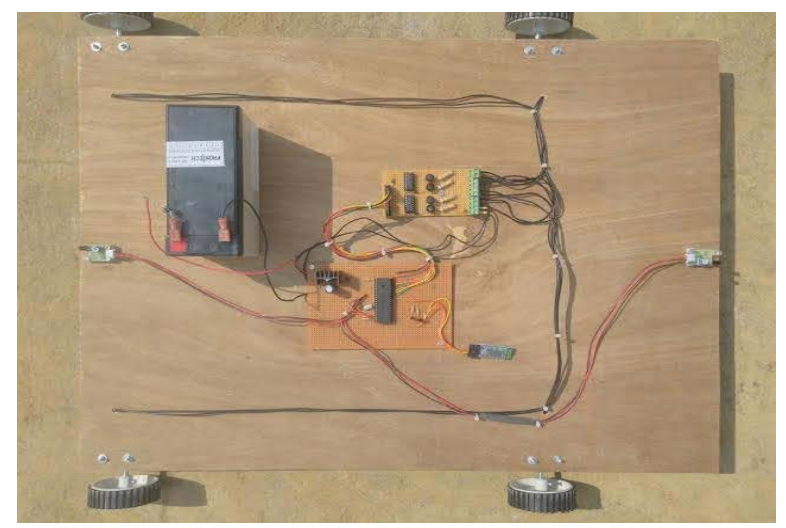

Figure 2. Connectivity with Android Phone.

It all right is also seen that there's a button to choose the Bluetooth gadget for example i.e. Figure 3. HC05 Bluetooth module as Connect. Client initially interfaces the versatile with the created framework.

At that point, the client can control the wheelchair with the assistance of different catches gave on the application interface.

\section{Output}

The proposed framework i.e., Figure $\mathbf{1}$ will have favorable position of profitability and vigor as the controlling relies upon android application that gives a UI through android application. Since this prototype is built only with capacity of carrying $10 \mathrm{KG}$ person weight. By using the high capacity supporting Motors, this prototype can be implemented as the real time application.

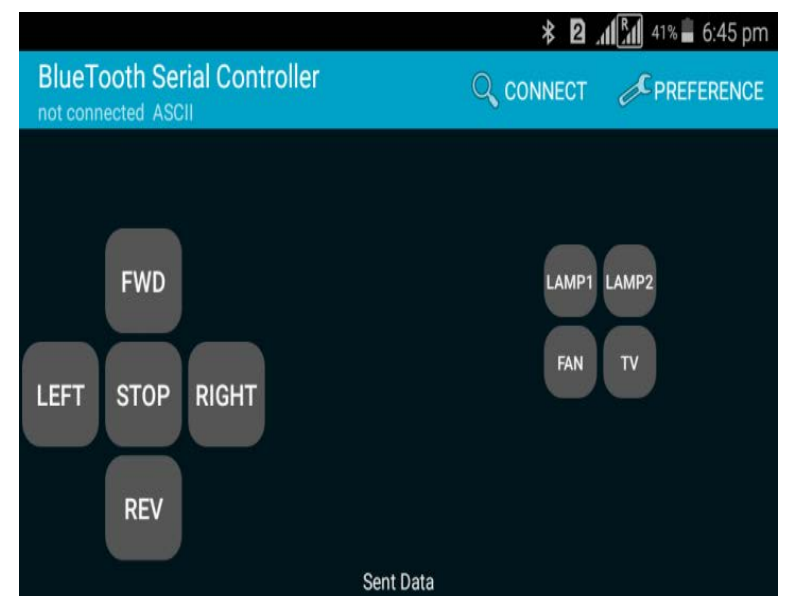

Figure 3. HC05 Bluetooth module as Connect.

\section{Future Scope}

The structure is modified in accordance with create it for the external condition by modifying the GPS space and therefore the client will decide on call to encounter it. The opposite means is that the means are going to be secured because the video and therefore the chair will travel naturally by perceiving totally different past patterns.

\section{Conclusion}

Utilizing this model the differently abled people can move starting with one place then onto the next without requiring assistance from other individual for turn on and off the fan, light and TV as well what's more, moreover without requiring physical pressure. The UI of humanoid application is crucial and straightforward to use to utilize. Deterrent discovery furnishes simplicity of route without crashing into articles in its direction. The reaction is speedy and precise.

\section{References}

1. Tadvi S, Adarkar P, Yadav AK, Saboo Siddik MH. Automated Wheelchair using Android Technology. Imperial Journal of Interdisciplinary Research (IJIR). 2016; 2(4):654-7.

2. Bhardwaj R, Gupta P, Jadhav P, Kadam B, Kedari A. Android Based Automated Smart Wheelchair. International Journal of Innovative Research in Computer and Communication Engineering. 2016; 4(3):3040-7. 
3. Kupkar P, Pandit P, Dhamdhere N, Jadhav PP. Android Controlled Wheel Chair. Imperial Journal of Interdisciplinary Research (IJIR). 2016; 2(6):1219-22.

4. Ankit V, Jigar P, Savan V. Obstacle avoidance robotic vehicle using ultrasonic sensor, android and bluetooth for obstacle detection. International Research Journal of Engineering and Technology (IRJET). 2016; 3(2):339-48.

5. Ramya Bhanu B, Ramesh D, Kantha Rao B. Google Android based Advanced Home Automation System using Android and Bluetooth Technologies. International Journal and Magazine of Engineering, Technology, Management and Research. 2015; 2:391-5.

6. Shaheen S, Umamakeswari A. Intelligent wheelchair for people with disabilities. International Journal of Engineering and Technology (IJET). 2012; 5(1):391-7.

7. Rofer T, Mandel C, Laue T. Controlling an automated wheelchair via joystick/head-joystick supported by smart driving assistance. International Conference on Rehabilitation Robotics; 2009. p. 743-8. https://doi. org/10.1109/ICORR.2009.5209506

8. Arungandhi A, Balaji DM, Singh BD. Android phone controlled voice, gesture and touch screen operated smart wheelchair. International Journal of Advanced Research in Electrical, Electronics and Instrumentation Engineering. 2016; 5(1):78-80.

9. Nirmal TM. Wheelchair for physically and mentally disabled person. International Journal of Electrical and Electronics Research. 2014; 2(2):112-8.

10. Nipanikar RS, Gaikwad V, Choudhari C, Gosavi R, Harne V. Automatic wheelchair for physically disabled persons. International Journal of Advanced Research in Electronics and Communication Engineering (IJARECE). 2013; 2(4):466-74. 